Presented at the 2003 Spring Meeting of the European Materials Research Society, Strasbourg, 10.13.6.2003

\title{
LATTICE LOCATION AND OPTICAL ACTIVATION OF RARE EARTH IMPLANTED
} GaN

\author{
U. Wahl, ${ }^{* 1}$ E. Alves, ${ }^{1}$ K. Lorenz, ${ }^{1}$ J.G. Correia, ${ }^{1}$ T. Monteiro, ${ }^{2}$ B. De Vries, ${ }^{3}$ A. Vantomme, ${ }^{3}$ \\ R. Vianden ${ }^{4}$ \\ ${ }^{1}$ Instituto Tecnológico e Nuclear, EN10, PT-2686-953 Sacavém, Portugal \\ ${ }^{2}$ Departamento de Física, Universidade de Aveiro, PT-3810 Aveiro, Portugal \\ ${ }^{3}$ Instituut voor Kern- en Stralingsfysica, Katholieke Universiteit Leuven, \\ B-3001 Leuven, Belgium \\ ${ }^{4}$ Helmholtz Institut für Strahlen- und Kernphysik, Universität Bonn, \\ D-53115 Bonn, Germany
}

\begin{abstract}
This paper reviews the current knowledge on rare earths (REs) implanted into GaN with a special focus on their lattice location and on the optical activation by means of thermal annealing. While emission channeling experiments have given information on the lattice location of rare earths following low-dose $\left(\approx 10^{13} \mathrm{~cm}^{-2}\right)$ implantation, both in the asimplanted state and after annealing up to $900^{\circ} \mathrm{C}$, the lattice location of higher-dose implants $\left(10^{14}-10^{15} \mathrm{~cm}^{-2}\right)$ and their defect annealing behaviour were studied using the Rutherford backscattering/channeling method. The available channeling and luminescence results suggest that the optical activation of implanted REs in GaN is related to their incorporation in substitutional Ga sites combined with the effective removal of the implantation damage.
\end{abstract}

Keywords: GaN, rare earth, ion implantation, channeling, luminescence

\section{Introduction}

Rare earth (RE) doped GaN is an interesting system with respect to applications in light-emitting devices and displays. It has been demonstrated first by Ennen et al. [1] that $\mathrm{Si}, \mathrm{GaAs}, \mathrm{GaP}$ and InP doped with Er exhibit narrow line width infrared (IR) luminescence due to intra- $4 f$ shell atomic transitions of this element. The general interest in RE doped wide band gap semiconductors such as $\mathrm{GaN}$, AlN, SiC, or, most recently, ZnO, increased considerably after Favennec et al. had pointed out the empirical rule that the quenching of the Er IR luminescence at room temperature decreases with increasing band gap of the material [2]. While most semiconductors show only rare earth related IR luminescence, Steckl et al. demonstrated that in GaN also visible RE luminescence is observed [3].

Suitable doping techniques for the realization of GaN:RE optical devices must fulfill the following requirements: a) introduction of REs in sufficient concentrations, b) the possibility for lateral patterning of the RE doping, c) incorporation into optically active sites, d) avoiding the introduction of defects which degrade the optical properties of $\mathrm{GaN}$, or ability to remove them. Basically three possibilities have been explored so far. While diffusion doping with REs has recently been tried but met with limited success [4], doping during growth and ion implantation both resulted in strong RE-related luminescence. However, while GaN doped with REs in situ during molecular beam epitaxy (MBE) growth is already close to feasible applications [5], ion implantation is still lagging behind. Implantation easily allows achieving high concentrations of rare earths, and, by means of masks, it also can meet the requirement of lateral patterning. This paper focuses on our present understanding of the remaining points c) and d), which are commonly refered to as "optical activation".

We review the current knowledge on ion implanted GaN:RE with a special focus on the lattice location of the implanted atoms and on the thermal annealing procedures. We first discuss experiments applying the emission channeling technique, which have given information on the lattice location of rare earths following low-dose $\left(\approx 10^{13} \mathrm{~cm}^{-2}\right) \mathrm{im}-$ plantation, both in the as-implanted state and following annealing up to $900^{\circ} \mathrm{C}$. The lattice location of higher-dose implants $\left(10^{14}-10^{15} \mathrm{~cm}^{-2}\right)$ and their defect annealing behaviour up to $1200^{\circ} \mathrm{C}$ were studied using the Rutherford backscattering/channeling (RBS/C) method. Finally we discuss the optical activation procedures by means of thermal annealing.

\section{Lattice location of low-dose RE implants by emission channeling}

The emission channeling method [6] makes use of the fact that charged particles emitted from radioactive isotopes in a single crystal experience channeling or blocking effects along crystallographic axes and planes, resulting in a highly anisotropic emission yield from the crystal surface. Since the channeling or blocking effects depend characteristically on the position of origin of the charged particle, detecting the charged particles as a function of emission angle from various crystallographic directions gives information on the lattice sites of the impurity. The angle-dependent emission yield is either measured by means of a position-sensitive detector [7] or by rotating the sample in front of a collimated detector. While a qualitative identification of lattice sites is usually possible from visual inspection of the emission patterns, more precise quantitative results rely on comparing the experimental data with theoretical calculations. Exam-

\footnotetext{
* Corresponding author: Tel +351-219946085; Fax +351-219941525; Email: uwahl@itn.mces.pt.
} 
ples for possible lattice sites of higher symmetry in $\mathrm{GaN}$ have been given in Ref. [8], including substitutional Ga ( $\mathrm{S}_{\mathrm{Ga}}$ ) and $\mathrm{N}\left(\mathrm{S}_{\mathrm{N}}\right)$ sites, bond-centered $(\mathrm{BC})$ and anti-bonding $(\mathrm{AB})$ sites both within and off the $c$-axis, the "hexagonal" sites $\mathrm{HG}$ and $\mathrm{HN}$, and the so-called $\mathrm{T}$ - and $\mathrm{O}$-sites. We note that in the wurtzite structure all sites along the $c$-axis (e.g. $\mathrm{S}_{\mathrm{Ga}}$, $\mathrm{S}_{\mathrm{N}}, \mathrm{T}, \mathrm{BC}-c$ or $\mathrm{AB}-c$ ) produce the same [0001] channeling patterns. The same applies to all sites along the interstitial axis (e.g. $\mathrm{HG}, \mathrm{HN}$ and $\mathrm{O}$ ) that is centered in the hexagon spanned by the mixed $\mathrm{Ga}$ and $\mathrm{N} c$-axis rows. Hence, more crystal directions have to be considered for unambiguous site identification. Suitable crystal axes with pure rows of Ga and $\mathrm{N}$ atoms are for instance the [1102], [1101], [2113], [2203], [2201] or [2116].

Although there also exist $\alpha$ emitting rare earth isotopes, only $\beta^{-}$or conversion electron (CE) emitting probes have been studied [8-11]. While $\beta^{-}$emission channeling experiments give direct information on the location of the probe atom during its decay, conversion electrons are emitted subsequent to a beta or electron capture decay from excited states of the daughter isotope. Hence, it should be noted that it cannot be excluded that conversion electron experiments may reflect certain characteristics of the specific decay, such as nuclear recoil or electronic excitation effects in the atomic shell, influencing the microscopic environment of the probe atoms.

The first emission channeling experiments on GaN:RE were done by Dalmer et al. [11] who examined the conversion electrons emitted by ${ }^{167 \mathrm{~m}} \mathrm{Er}$ resulting from the decay of ${ }^{167} \mathrm{Tm}$ and by ${ }^{169 *} \mathrm{Tm}$ resulting from ${ }^{169} \mathrm{Yb}$. However, only $c$-axis angular scans were compared to simulations, with the best fit in all cases obtained for 90(10)\% of RE atoms on sites showing displacements of $0.25 \AA$ from the $c$-axis, both in the as-implanted state $\left(60 \mathrm{keV}, 2 \times 10^{13} \mathrm{~cm}^{-2}\right)$ and following vacuum annealing at $800^{\circ} \mathrm{C}$.

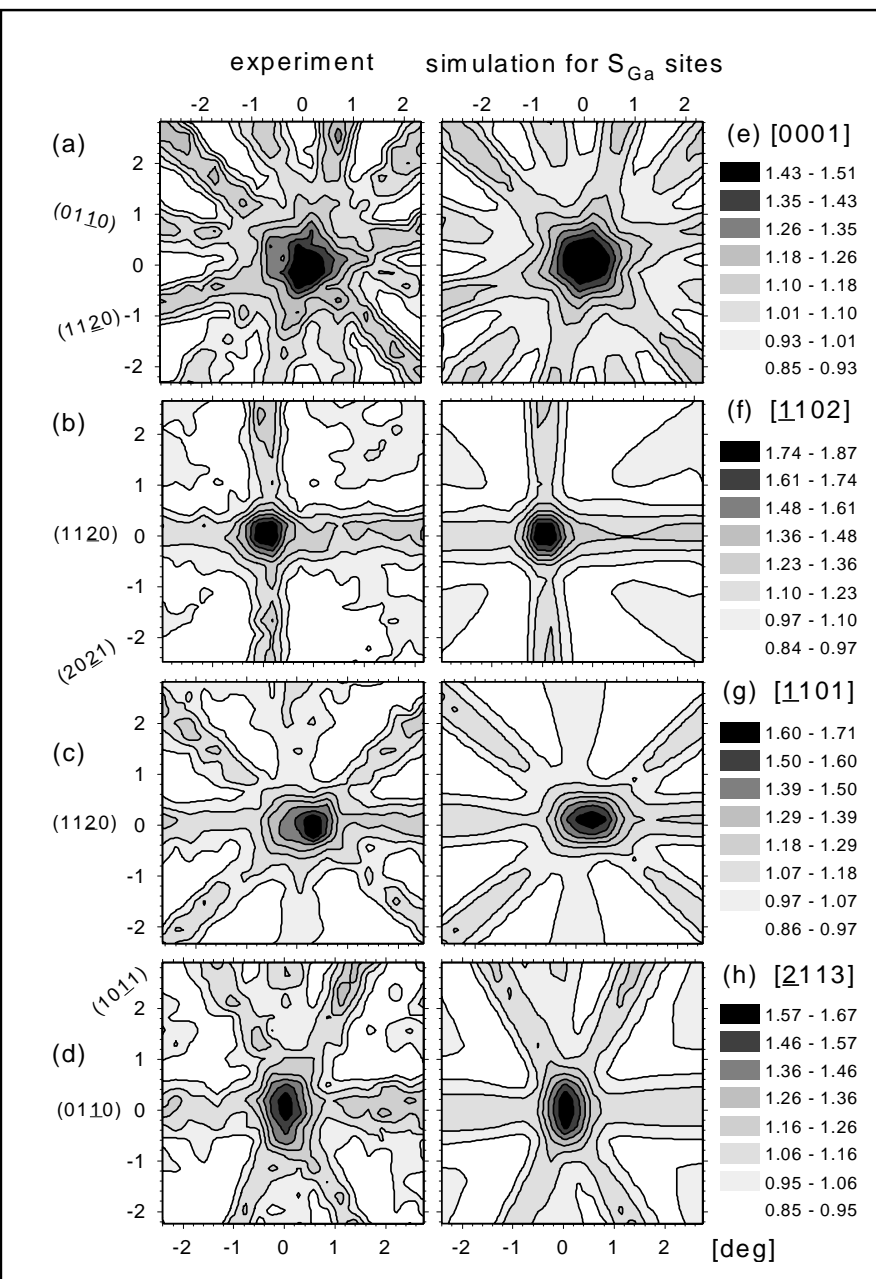

Fig. 1: Normalized angular-dependent $\beta^{-}$emission yields from as-implanted ${ }^{147} \mathrm{Nd}$ in $\mathrm{GaN}$ around the crystalline axes (a) [0001], (b) [1102], (c) [1101] and (d) [2113]. Panels (f)(h) represent the best fit of theoretical patterns for substitutional Ga sites to the experimental data.
By means of position-sensitive detectors, highly efficient emission channeling experiments can be done at low fluences of implanted rare earths, thus avoiding damage accumulation due to overlapping cascades, and giving information on the RE lattice location in the as-implanted state and following various annealing steps. As an example we show in Figs. 1 (a)-(d) the [0001], [1102], [1101] and [2113] $\beta^{-}$emission channeling patterns obtained following room temperature implantation of $60 \mathrm{keV}{ }^{147} \mathrm{Nd}$ at a fluence of $1 \times 10^{13} \mathrm{~cm}^{-2}$ into a $\mathrm{GaN}$ thin film grown on sapphire. Panels (f)-(h) represent the best twofraction fits of theoretical patterns to the experimental data, corresponding to $80 \%, 66 \%, 62 \%$, and $63 \%$ of $\mathrm{Nd}$ atoms on substitutional $\mathrm{Ga}$ sites $S_{\mathrm{Ga}}$, with root mean square $(\mathrm{rms})$ displacements perpendicular to the corresponding axes of $u_{1}(\mathrm{Nd})=0.24 \AA, 0.16 \AA$, $0.16 \AA$, and $0.20 \AA$, respectively [9]. Besides ${ }^{147} \mathrm{Nd}$, $\beta^{-}$emission channeling has been studied from ${ }^{143} \mathrm{Pr}$ [8], and CE emission channeling from ${ }^{147} \mathrm{Nd} \rightarrow{ }^{147} * \mathrm{Pm}$ [9] and ${ }^{149} \mathrm{Gd} \rightarrow{ }^{149 *} \mathrm{Eu}[10]$. The results of these experiments are compiled in Fig. 2. In all cases the majority of RE atoms (around 65$83 \%$ ) were found on substitutional Ga sites. In each case the possibility for other lattice sites than $\mathrm{S}_{\mathrm{Ga}}$ was investigated by introducing additional fractions into the fits. However, possible fractions on other highly symmetric sites must be below 5-7\%. Compared to the as-implanted state, the substitutional fractions hardly changed following 10-min annealing sequences up to $900^{\circ} \mathrm{C}$ under vacuum, whereas the rms displacements from the $S_{\mathrm{Ga}}$ sites decreased slightly with annealing temperature. The decrease in rms displacement points out a more perfect substitutional incorporation of the RE atoms and is in fact the only observation of damage annealing in these low-dose experiments. The variations in rms displacements perpendicular to the four different channeling directions for each experiment, and from isotope to isotope indicate that different rare earth atoms experience small static displacements along well-defined crystallographic directions. However,

more experiments with additional isotopes will be needed to confirm systematic trends in that respect. 


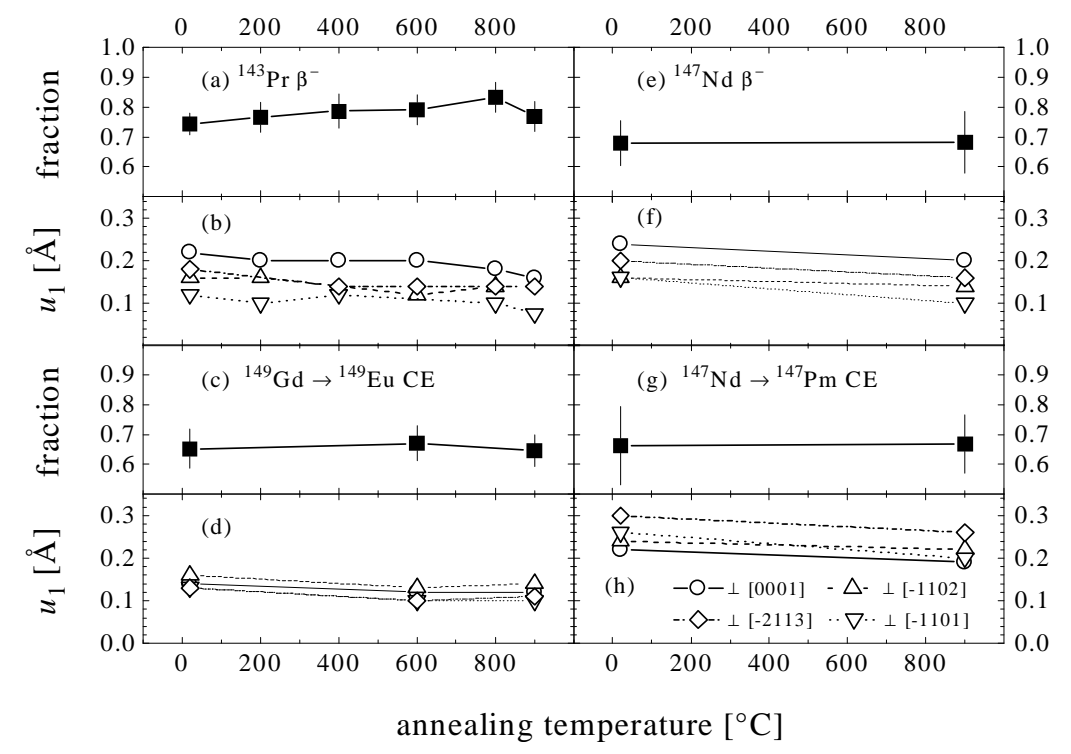

Fig. 2: Fraction of rare earths on substitutional Ga sites and their rms displacements perpendicular to the channeling directions as function of annealing temperature. All implantations were done with $60 \mathrm{keV}$ at room temperature $7^{\circ}$ off the surface direction with fluences of $1 \times 10^{13} \mathrm{~cm}^{-2}$ for ${ }^{143} \mathrm{Pr}$ and ${ }^{147} \mathrm{Nd}$, and $2 \times 10^{13} \mathrm{~cm}^{-2}$ for ${ }^{149} \mathrm{Gd}$. Note that the decay ${ }^{147} \mathrm{Nd}\left(\beta^{-}\right) \rightarrow{ }^{147 *} \mathrm{Pm}(\mathrm{CE}) \rightarrow{ }^{147} \mathrm{Pm}$ allows to simultaneously measure both $\beta^{-}$and conversion electrons (CE).

\section{Lattice location of higher-dose RE implants by RBS/C}

The well-known Rutherford backscattering channeling (RBS/C) method allows studying the depth profiles and RE lattice location for higher dose implants as well as the related implantation damage. Measurements have been done for GaN samples implanted at energies of $150-160 \mathrm{keV}$ with fluences in the range $5 \times 10^{14} \mathrm{~cm}^{-2}$ to $1 \times 10^{16} \mathrm{~cm}^{-2}$. The efficiency of RBS is smaller than emission channeling, and only one-dimensional scans through the [0001] and [1011] axes have been measured. Note that the [1011] axis is a crystalline direction equivalent to [1101], which allows distinguishing between substitutional Ga and $\mathrm{N}$ and interstitial sites. Following room temperature implantation of $5 \times 10^{14} \mathrm{~cm}^{-2} \mathrm{Er}$ the [0001] RBS scans from Er and Ga atoms overlapped completely, reaching a minimum yield around 0.30, in comparison to 0.02 for a virgin crystal $[12,13]$. In other terms, with respect to the $c$-axis, $100 \%$ of Er atoms had on average the same locations as the Ga atoms, of which around $30 \%$ were randomly distributed in the lattice. Annealing around $600^{\circ} \mathrm{C}$ starts the damage recovery, however, even following annealing at $1000^{\circ} \mathrm{C}$ for 2 min under flowing $\mathrm{N}_{2}$ it is not complete and at best only minimum Ga RBS yields down to around 0.10 were achieved. Only annealing at $1200^{\circ} \mathrm{C}$ under $1 \mathrm{GPa}$ of nitrogen (done at the Unipress Institute in Warsaw) occasionally resulted in samples where the RBS Ga yield was again similar to virgin samples [14].

Fig. 3 compiles the [0001] and [1011] angular RBS scans obtained for the RE elements Ce, $\operatorname{Pr}[15,16], \mathrm{Eu}[15$, 16], Dy, Er, Tm [17], and Lu. While annealing of the GaN:Er sample was carried out at $1200^{\circ} \mathrm{C}$ under $1 \mathrm{GPa}$ of $\mathrm{N}_{2}$ for $20 \mathrm{~min}$, all the other samples were annealed for $2 \mathrm{~min}$ at $1000^{\circ} \mathrm{C}$ under flowing $\mathrm{N}_{2}$. The [0001] minimum yields for $\mathrm{Ga}$ vary between 0.08 and 0.44 , scaling with the fluences that ranged from $7 \times 10^{14} \mathrm{~cm}^{-2}$ (Ce and Tm) to $1.5 \times 10^{15} \mathrm{~cm}^{-2}(\mathrm{Eu})$. From the fact that the RE and Ga scans overlap along both the [0001] and [1011] directions it is clear that the majority of the REs occupies substitutional Ga sites. We note that substitutional $\mathrm{N}$ sites would lead to considerably narrower angular widths of the [1011] scans, whereas interstitial sites such as T, O or H would cause peaks along the [0001] or [1011] or both. Taking the Ga scan for each sample as $100 \%$ reference, we arrive at the result that $97 \%$ of Ce, $81 \%$ of Pr, $100 \%$ of Eu, $96 \%$ of Dy, $78 \%$ of Er, $83 \%$ of Tm, and $82 \%$ of Lu atoms occupy the same sites as Ga (which are not all ideal substitutional sites due to the remaining damage).

Deriving precise values for the RE rms displacements from $S_{\mathrm{Ga}}$ positions is difficult on account that the azimuthal orientations of the scans are not accurately known and the angular widths are distorted by remaining implantation damage. This can be seen from the fact that the simulated Ga yields shown in Fig. 3 do not completely overlap with the Ga RBS scans. However, in all cases except one, the angular width of the Ga and REs scans matched, which points out that the rms displacements of the REs must be similar to those of Ga. The simulated RE scans shown in Fig. 3 were calculated for rms displacements of $0.07 \AA$. The [1011] scan of Eu represents the only exception, here $u_{1}(\mathrm{Eu})=0.14 \AA$ had to be chosen. A possible explanation for this could be that Eu is displaced around $0.20 \AA$ along the [0001] direction, leading to an overlap with the Ga scan along [0001] but to a displacement of $0.14 \AA=0.20 \AA \sin \left(46.8^{\circ}\right)$ if projected perpendicular to [1011]. Here we would also like to correct a mistake in one of our previous publications [16], where it 
was argued that a [0001] displacement of Eu could explain a lower symmetry than $C_{3 v}$ of the PL spectra. We would like to clarify that a displacement along [0001] does not break the trigonal $C_{3 v}$ symmetry.

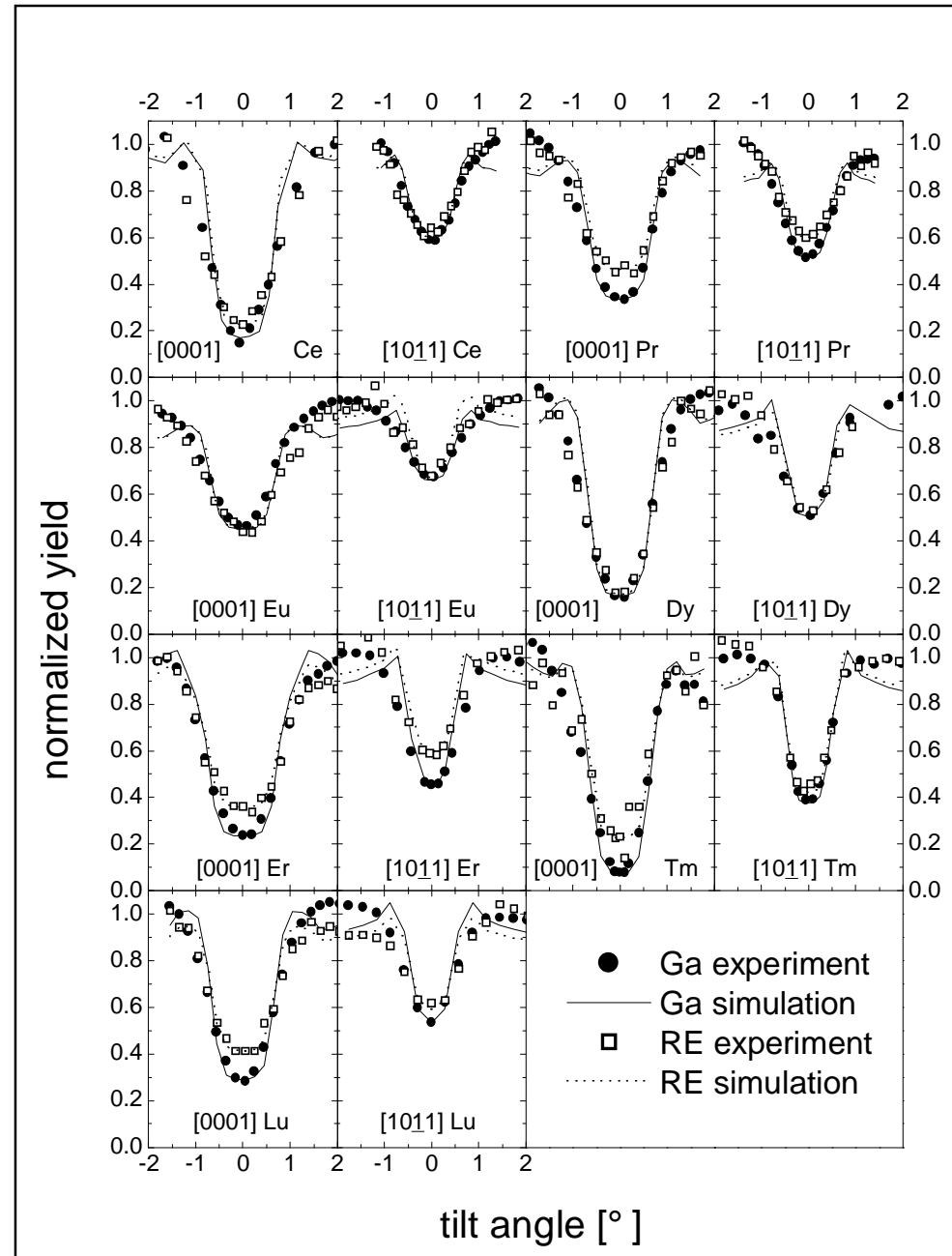

Fig. 3: [0001] and [1011] angular RBS scans for Ga and various REs in comparison to the best fits of Monte Carlo simulations for substitutional Ga sites. The analyzing beam was $2 \mathrm{MeV}{ }^{4} \mathrm{He}$. All REs were implanted with $160 \mathrm{keV}$ at room temperature up to fluences of $7 \times 10^{14} \mathrm{~cm}^{-2}(\mathrm{Ce}), 1.2 \times 10^{15} \mathrm{~cm}^{-2}(\mathrm{Pr}), 1.5 \times 10^{15} \mathrm{~cm}^{-2}(\mathrm{Eu}), 8 \times 10^{14} \mathrm{~cm}^{-2}$ (Dy), $5 \times 10^{14} \mathrm{~cm}^{-2}(\mathrm{Er}), 7 \times 10^{14} \mathrm{~cm}^{-2}(\mathrm{Tm})$, and $9 \times 10^{14} \mathrm{~cm}^{-2}(\mathrm{Lu})$, roughly along the surface direction. The RE rms displacements used in the simulations were in all cases equal to the thermal displacements of Ga $(0.07 \AA)$, except for the Eu rms displacement perpendicular to the [1011] direction, where $0.14 \AA$ was used.
For much higher fluences, around $5 \times 10^{15} \mathrm{~cm}^{-2}$, the implanted GaN layer is completely amorphized and no lattice location experiments are possible without prior annealing at temperatures above $900^{\circ} \mathrm{C}[12-15,17,18]$. While epitaxial regrowth takes place at $1000^{\circ} \mathrm{C}$ with a rate around $100 \AA / \mathrm{min}$, only annealing at $1200^{\circ} \mathrm{C}$ under $1 \mathrm{GPa}$ of nitrogen has so far been successful in achieving nearcomplete recovery in some cases [14], while in others the reproducibility of the high-temperature high-pressure treatment proved to be not entirely reliable. In the case of Er, the maximum substitutional fractions for these high-dose implanted samples were around $30-50 \%$ with a possible contribution of some $\mathrm{Er}$ displaced along the $c$-axis [19].

Care should also be taken about the evolution of the RE depth profiles during high-temperature annealing. So far this has been studied in more detail only for Er. While no change in the Er depth profile was observed up to $900^{\circ} \mathrm{C}$, a shift towards the surface started during annealing at $1000^{\circ} \mathrm{C}$. Annealing at $1200^{\circ} \mathrm{C}$ caused significant changes in the Er profile, either due to loss of $\mathrm{GaN}$ itself or parts of Er being lost through the surface or diffusing deeply into GaN. The maximum remaining Er concentration was found to be around 0.35 at\% [14].

\section{Optical activation}

No RE related luminescence has been reported from as-implanted GaN, and thermal annealing is an essential step for its activation. Table 1 gives an overview about the publications which have dealt with the luminescence from implanted rare earths in GaN. In each case we have included the investigated element, type of luminescence experiment, and possible information given on the rare earth lattice sites and/or number and symmetry of the luminescence centers. With respect to the implantation energy and fluence, the temperature, duration and atmosphere of the annealing step(s), we note that we have tried to quote the optimum parameters leading to the highest luminescence output given in each publication. We would like to point out, however, that this may be somewhat misleading, since some authors have investigated a wider range of implantation fluences and annealing procedures, while others have only reported the data for one successful attempt. So far, characteristic luminescence from intra- $f$ shell transitions of trivalent $\mathrm{RE}^{3+}$ has been reported for implantations of most of the rare earth elements except $\mathrm{Ce}, \mathrm{Pm}, \mathrm{Gd}, \mathrm{Yb}$ and $\mathrm{Lu}$. The majority of studies, however, investigated the Er IR luminescence, which, along with Pr and Eu visible luminescence, seems not difficult to be achieved, while, e.g., the Er green and Tm blue luminescence are more challenging. 
As can be seen, most work has focused on the dose range $10^{14}-5 \times 10^{15} \mathrm{~cm}^{-2}$, with implantation energies of a few ten $\mathrm{keV}$ up to the $\mathrm{MeV}$ range. Those who studied luminescence from samples implanted at varying doses [14, 18, $19,22,23,49-53]$ generally found that implantations in the $1-5 \times 10^{15} \mathrm{~cm}^{-2}$ range gave stronger luminescence than lower doses. At higher fluences the inability to regrow a crystalline GaN layer from the amorphous state presents a limit. With respect to the applied annealing temperatures, there has been an upward trend in time. While most studies before 1998 reported only results for the temperature range below $1000^{\circ} \mathrm{C}$, newer work focuses increasingly on temperatures at $1100^{\circ} \mathrm{C}$ and above. Three papers have investigated whether the luminescence intensity of implanted GaN:Er depends on the type of starting material, and found no striking differences between MBE, HVPE or MOCVD GaN [20, 22, 36].

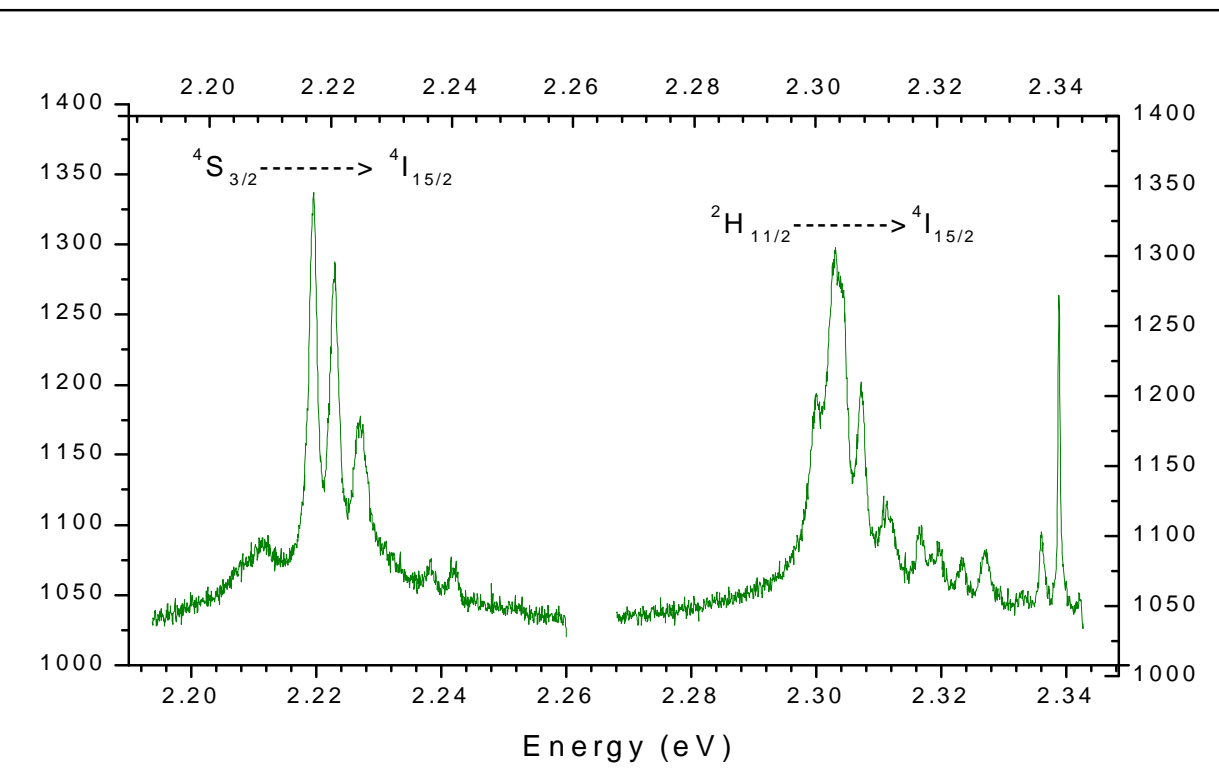

Fig.4: Photoluminescence spectrum showing the green emissions of GaN implanted with $5 \times 10^{15} \mathrm{Er}^{+} \mathrm{cm}^{-2}$ at $550^{\circ} \mathrm{C}$ followed by annealing at $1200^{\circ} \mathrm{C}$ under $1 \mathrm{GPa}$ of $\mathrm{N}_{2}$ for $20 \mathrm{~min}$.
Another issue which is being discussed controversially, is oxygen co-doping. It is interesting to note that for GaN doped with Er during MOMBE growth it was reported that $\mathrm{O}$ or $\mathrm{C}$ co-doping increases the IR photoluminescence (PL) for below-gap excitation (457-514 nm) but not for above-gap excitation (334-364 $\mathrm{nm})$ [29]. In addition, the room temperature quenching of the PL from $\mathrm{GaN}$ :Er,O was found to be different from GaN:Er. With respect to implanted samples, $\mathrm{O}$ coimplantation, generally in the fluence range Er:O $=1: 1$ to $1: 10$, is reported to be beneficial for annealing temperatures up to $900^{\circ} \mathrm{C}[12,24$, $48,50-53,58,59]$. All of these studies investigated the Er IR emission, applying partly below-gap and partly above-gap excitation PL, or cathodo- or electroluminescence. On the other hand, for samples annealed at temperatures above $900^{\circ} \mathrm{C}$ the IR PL of GaN:Er,O was reported to be inferior to $\mathrm{GaN}: \mathrm{Er}[14,19,24,58]$. However, all of the latter three studies applied below-gap excitation. There is also a report that co-implanting with $\mathrm{F}$ is beneficial for the Er IR luminescence [51]. In this case annealing temperatures stayed below $900^{\circ} \mathrm{C}$, too. For $\mathrm{GaN}: \mathrm{Pr}, \mathrm{O}$ with above-gap excitation lower visible and IR PL intensity is reported than for GaN:Pr [25, 57]. Summarizing, the question of co-doping seems not to be settled.

With respect to annealing atmospheres, $\mathrm{N}_{2}$ under atmospheric pressure was reported as best choice in most cases, although also $\mathrm{NH}_{3}$, forming gas $\left(\mathrm{NH}_{3}+\mathrm{H}_{2}\right), \mathrm{O}_{2}$ or $\mathrm{Ar}$ are quoted as well-suited in some cases. Our personal experience is that samples that were annealed at $1200^{\circ} \mathrm{C}$ under the high nitrogen pressure of $1 \mathrm{GPa}=9.9 \mathrm{kbar}$ at the Unipress Institute in Warsaw showed very sharp Er IR PL linewidths. In addition, these were also the only samples for which we found well-resolved (Fig. 4) visible photoluminescence from implanted Er [19], while visible Er cathodoluminescence has been reported elsewhere [23, 38].

In some cases the observed intensities for the RE luminescent transitions have been compared to theoretical predictions from lattice sum calculations in order to assess the symmetry properties of the participating RE defects. In these cases it was found that the luminescence spectra of $\operatorname{Pr}[16,42,43,60]$ and $\mathrm{Sm}$ [26] are compatible with $C_{3 v}$ symmetry, while Tb luminescence was probably related to defects of $D_{2}$ symmetry [27]. In the case of Eu, $C_{3 v}$ symmetry [44] and $D_{2}$ [16] were suggested. In any case, extracting symmetry information of rare earth centers is considered to be difficult because contributions from many different centers may be superimposed together with vibronic and satellite lines [16, 39, 40]. Valuable information on the existence of different centers contributing to the IR luminescence of implanted Er has emerged from experiments were the photoluminescence was studied as a function of wavelength of the exciting light, a technique often referred to as "site"-selective excitation. The results have revealed that there are up to 9 different Er centers involved in its IR luminescence [19, 29-37, 45, 46-47, 49, 52, 54, 61].

\section{Discussion}

It is clear from the available emission channeling data that following low-dose implantation $\left(\approx 10^{13} \mathrm{~cm}^{-2}\right)$ the majority of REs are directly incorporated into $S_{\mathrm{Ga}}$ sites without requiring any thermal treatment. RBS has shown this even for implanted fluences up to $5 \times 10^{14} \mathrm{~cm}^{-2}$. The fact that strongest luminescence is observed for samples which show high fractions of REs on substitutional Ga sites combined with effective implantation damage annealing, makes it very tempting 
to associate these two conditions with optical activation. Moreover, so far no experimental data have been reported by any technique identifying REs in GaN occupying well-specified other lattice sites than substitutional Ga sites or positions very close $(<0.3 \mathrm{~A})$ to $S_{\mathrm{Ga}}$. However, all direct lattice location measurements have also shown random RE fractions of at least $10 \%$. These random fractions can have several causes. First of all, both in RBS and emission channeling it is only in exceptional cases possible to assess more than the one or two most frequently occupied lattice positions. Therefore, if an impurity atom occupies many different lattice sites of low symmetry, both methods would see an almost isotropic contribution to the angular yield. Moreover, the emission channeling technique suffers from the fact that there is no reference signal from the Ga atoms available. Since the analysis is based on the assumption of a perfect lattice, this means that all imperfections in crystal quality, resulting from implantation damage or imperfect growth, will reduce the apparent fractions below $100 \%$. In addition, all measurements have to be corrected for the influence of electrons backscattered from the sample and the walls of the vacuum chamber. This is usually done by means of Monte Carlo simulations, and the estimated accuracy of the fractions is around 15-20\%. While the influence of crystal quality can be corrected in RBS to some extent by a comparison of the Ga and RE signal, the lower sensitivity of the RBS method requires higher doses of implanted rare earths, making it difficult to study samples without interference of damage.

Comparing the channeling results to the luminescence data requires some care, and the following points should be considered. The symmetry of the intact first atomic neighbour shells around perfect $S_{\mathrm{Ga}}, S_{\mathrm{N}}$ and $T$ positions is close to tetrahedral $\left(T_{d}\right)$. All lattice sites along the $c$-axis and along the main interstitial axis parallel to the $c$-axis in GaN possess strict trigonal $\left(C_{3 v}\right)$ symmetry. In any case, it is unknown, for instance, how far a rare earth atom would have to be displaced off the $c$-axis in order to reveal a symmetry lower than $C_{3 v}$ in luminescence experiments. An important point is also that luminescence experiments cannot well quantify the absolute number of centers responsible for producing a detected signal. Hence it cannot be ruled out that a luminescence signal originates only from a comparatively small amount of implanted atoms. This is illustrated by the fact that there is no linear correlation between the implanted fluences and the intensity of the luminescence signals. We also would like to point out that the term "site"-sensitive for photoluminescence excitation spectroscopy is somewhat misleading, and suggest it should rather be named "center"sensitive. The reason is that it is possible that impurity atoms in two structurally different complexes occupy the same lattice site but are surrounded by neighbours in different atomic configurations.

Further approaches in order to optimize the luminescence from implanted REs in GaN should combine all possible means in order to reduce damage creation during implantation, i.e. channeled implantation [55, 62], implantation at elevated temperatures $[18,55,62]$, multiple energy implants ranging from several $10 \mathrm{keV}$ up to the MeV region, in order to introduce a large amount of RE atoms at low local concentrations of damage [26, 27, 38-44, 54]. While highpressure $(1 \mathrm{GPa})$ high-temperature $\left(1200^{\circ} \mathrm{C}\right)$ annealing of $\mathrm{GaN}$ has lead to promising results, the process still has some problems with reproducibility and is not feasible for device production. Our groups are therefore exploring the usefulness of less aggressive annealing steps at temperatures around $1100^{\circ} \mathrm{C}$ and moderate $\mathrm{N}_{2}$ pressures of several bar only.

\section{Conclusions}

Evidence has been presented for the hypothesis that the optical activation of implanted REs in GaN is related to their incorporation in substitutional Ga sites combined with the effective removal of the implantation damage. Incorporation of the REs in these sites is easy and already takes place to a large extent during the implantation provided the samples are not amorphized. The most promising approach with respect to maximizing the optical activation of RE implants should therefore focus on minimizing the created implantation damage and further optimizing its annealing procedures.

\section{Acknowledgments}

UW acknowledges his fellowship from the Foundation for Science and Technology/Portugal (FCT), BDV his Research Assistant fellowship from the Fund for Scientific Research Flanders/Belgium (FWO-Vlaanderen). In addition, this work was funded by the FCT project CERN/FIS/43725/2001, and by the European Commission through the RENiBEl (Rare Earth doped Nitrides for high Brightness Electroluminescent emitters) network and the HPRI program (Large Scale Facility contract Nr HPRI-CT-1999-00018).

\section{References:}

[1] H. Ennen, J. Schneider, G. Pomrenke, A. Axmann, Appl. Phys. Lett. 43 (1983) 943.

[2] P.N. Favennec, H. L’Haridon, M. Salvi, D. Moutonnet, Y.L. Guillou, Electron. Lett. 25 (1989) 718.

[3] A.J. Steckl, R. Birkhahn, Appl. Phys. Lett. 73 (1998) 1700.

[4] Y.S. Ting, C.C. Chen, C.C. Lee, G.C. Chi, T.P. Chini, P. Chakraborty, H.W. Chuang, J.S. Tsang, C.T. Kuo, W.C. Tsai, S.H. Chen, J.I. Chyi, Opt. Mater. (2003) in press.

[5] Y.Q. Wang, A.J. Steckl, Appl. Phys. Lett. 82 (2003) 502.

[6] H. Hofsäss, G. Lindner, Phys. Rep. 210 (1991) 121.

[7] U. Wahl, J.G. Correia, S. Cardoso, J.G. Marques, A. Vantomme, G. Langouche, the ISOLDE collaboration, Nucl. Instr. Meth. in Physics Research B 136 (1998) 744.

[8] U. Wahl, A. Vantomme, G. Langouche, J.P. Araujo, L. Peralta, G. Correia, the ISOLDE collaboration, J. Appl. Phys. 88 (2000) 1319.

[9] B. De Vries, U. Wahl, A. Vantomme, J.G. Correia, the ISOLDE collaboration, phys. stat. sol. (c) 0 (2002) 453.

[10] B. De Vries, U. Wahl, A. Vantomme, J.G. Correia, the ISOLDE collaboration, this conference, contribution J/P.28. 
[11] M. Dalmer, M. Restle, A. Stötzler, U. Vetter, H. Hofsäss, M.D. Bremser, C. Ronning, R.F. Davies, Mat. Res. Soc. Symp. Proc. 482 (1998) 1021.

[12] E. Alves, M.F. da Silva, J.C. Soares, R. Vianden, J. Bartels, A. Kozanecki, Nuclear Instr. Meth. in Physics Research B 147 (1999) 383.

[13] E. Alves, M.F. da Silva, J.C. Soares, R. Vianden, C.R. Abernathy, S.J. Pearton, MRS Internet J. Nitride Semicond. Res. 4S1 (1999) G11.2.

[14] E. Alves, T. Monteiro, J. Soares, L. Santos, M.F. da Silva, J.C. Soares, W. Lojkowski, D. Kolesnikov, R. Vianden, J.G. Correia, Mater. Sci. Eng. B 81 (2001) 132.

[15] E. Alves, K. Lorenz, R. Vianden, C. Boemare, M.J. Soares, T. Monteiro, Mod. Phys. Lett. 15 (2001) 1281.

[16] T. Monteiro, C.Boemare, M.J. Soares, R.A. Sá Ferreira, L.D. Carlos, K. Lorenz, R. Vianden, E. Alves, Physica B 308 (2001) 22.

[17] K. Lorenz, E. Alves, U. Wahl, T. Monteiro, S. Dalmasso, R.W. Martin, K.P. O' Donnell, R. Vianden, this coference, contribution J-IV.3.

[18] E. Alves, C. Liu, M.F. da Silva, J.C. Soares, R. Correia, T. Monteiro, Mat. Res. Soc. Symp. Proc. 647 (2001) O13.4.

[19] T. Monteiro, J. Soares, M.R. Correia, E. Alves, J. Appl. Phys. 89 (2001) 6183.

[20] L.C. Chao, A.J. Steckl, Appl. Phys. Lett. 74 (1999) 2364.

[21] L.C. Chao, B.K. Lee, C.J. Chi, J. Cheng, I. Chyr, A.J. Steckl, J. Vac. Sci. Technol. B 17 (1999) 2791.

[22] L.C. Chao, B.K. Lee, C.J. Chi, J. Cheng, I. Chyr, A.J. Steckl, Appl. Phys. Lett. 75 (1999) 1833.

[23] S. Dalmasso, R.W. Martin, P.R. Edwards, K.P. O’Donnell, B. Pipeleers, A. Vantomme, Y. Nakanishi, A. Wakahara, A. Yoshida, Mat. Res. Soc. Symp. Proc. 743 (2003) L6.15.

[24], V. Yu Davydov, V.V. Lundin, A.N. Smirnov, N.A. Sobolev, A.S. Usikov, A.M. Emel'yanov, M.I. Makoviichuk, E.O. Parshin, Semiconductors 33 (1999) 1.

[25] C.J. Ellis, R.M. Mair, J. Li, J.Y. Lin, H.X. Jiang, J.M. Zavada, R.G. Wilson, Mater. Sci. Eng. B 81 (2001) 167.

[26] J.B. Gruber, B. Zandi, H.J. Lozykowski, W.M. Jadwisienczak, J. Appl. Phys. 91 (2002) 2929.

[27] J.B. Gruber, B. Zandi, H.J. Lozykowski, W.M. Jadwisienczak, J. Appl. Phys. 92 (2002) 5127.

[28] D.M. Hansen, R. Zhang, N.R. Perkins, S. Safvi, L. Zhang, K.L. Bray, T.F. Kuech, Appl. Phys. Lett. 72 (1998) 1244.

[29] U. Hömmerich, M. Thaik, T. Robinson-Brown, J.D. MacKenzie, C.R. Abernathy, S.J. Pearton, R.G. Wilson, R.N. Schwartz, J.M. Zavada, Mat. Res. Soc. Symp. Proc. 482 (1998) 685.

[30] M. Thaik, U. Hömmerich, R.N. Schwartz, R.G. Wilson, and J.M. Zavada, Appl. Phys. Lett. 71 (1997) 2641.

[31] S. Kim, S.J. Rhee, D.A. Turnbull, E.E. Reuter, X. Li, J.J. Coleman, S.G. Bishop, Appl. Phys. Lett. 71 (1997) 231.

[32] S. Kim, S.J. Rhee, D.A. Turnbull, X. Li, J.J. Coleman, S.G. Bishop, Mat. Res. Soc. Symp. Proc. 468 (1997) 131.

[33] S. Kim, S.J. Rhee, X. Li, J.J. Coleman, S.G. Bishop, Phys. Rev. B 57 (1998) 14588.

[34] S. Kim, X. Li, J.J. Coleman, R. Zhang, D.M. Hansen, T.F. Kuech, S.G. Bishop, MRS Internet J. Nitride Semicond. Res. 4S1 (1999) G11.4.

[35] S. Kim, S.J. Rhee, X. Li, J.J. Coleman, S.G. Bishop, Appl. Phys. Lett. 76 (2000) 2403.

[36] S. Kim, R.L. Henry, A.E. Wickenden, D.D. Koleske, S.J. Rhee, J.O. White, J.M. Myoung, K. Kim, X. Li, J.J. Coleman, S.G. Bishop, J. Appl. Phys. 90 (2001) 252.

[37] S. Kim, S.J. Rhee, J.O. White, A.M. Mitofsky, X. Li, G.C. Papen, J.J. Coleman, S.G. Bishop, Mater. Sci. Eng. B 81 (2001) 136.

[38] H.J. Lozykowski, W.M. Jadwiszienczak, I. Brown, Appl. Phys. Lett. 74 (1999) 1129.

[39] H.J. Lozykowski, W.M. Jadwiszienczak, I. Brown, Sol. State Comm. 110 (1999) 253.

[40] H.J. Lozykowski, W.M. Jadwiszienczak, I. Brown, Appl. Phys. Lett. 76 (2000) 861.

[41] H.J. Lozykowski, W.M. Jadwiszienczak, I. Brown, Mater. Sci. Eng. B 81 (2001) 140.

[42] H.J. Lozykowski, W.M. Jadwiszienczak, I. Brown, MRS Internet J. Nitride Semicond. Res. 5S1 (1999) W11.64.

[43] H.J. Lozykowski, W.M. Jadwiszienczak, I. Brown, J. Appl. Phys. 88 (2000) 210.

[44] H.J. Lozykowski, W.M. Jadwiszienczak, J. Han, I. Brown, Appl. Phys. Lett. 77 (2000) 767.

[45] A.M. Mitofsky, G.C. Papen, S.G. Bishop, D.S. Lee, A.J. Steckl, Mat. Res. Soc. Symp. Proc. 639 (2001) G6.26.

[46] H. Przybylinska, W. Jantsch, A. Kozanecki, Mater. Sci. Eng. B 81 (2001) 147.

[47] H. Przybylinska, A. Kozanecki, V. Glukhanyuk, W. Jantsch, D.J. As, K. Lischka, Mater. Sci. Eng. B 81 (2001) 34.

[48] C.H. Qiu, M.W. Leksono, J.I. Pankove, J.T. Torvik, R.J. Feuerstein, F. Namavar, Appl. Phys. Lett. 66 (1995) 562.

[49] S.J. Rhee, S. Kim, C.W. Sterner, J.O. White, S.G. Bishop, J. Appl. Phys. 90 (2001) 2760.

[50] J.T. Torvik, R.J. Feuerstein, J.I.Pankove, C.H. Qiu, F. Namavar, Appl. Phys. Lett. 69 (1996) 2098.

[51] J.T. Torvik, C.H. Qiu, R.J. Feuerstein, J.I.Pankove, F. Namavar, J. Appl. Phys. 81 (1997) 6343.

[52] J.T. Torvik, R.J. Feuerstein, C.H. Qiu, J.I.Pankove, F. Namavar, J. Appl. Phys. 82 (1997) 1824.

[53] J.T. Torvik, R.J. Feuerstein, C.H. Qiu, J.I.Pankove, F. Namavar, Mat. Res. Soc. Symp. Proc. 482 (1998) 579.

[54] S. Uekusa, T. Hirano, Mat. Res. Soc. Symp. Proc. 639 (2001) G6.15.

[55] A. Vantomme, S.M. Hogg, M.F. Wu, B. Pipeleers, M. Swart, S. Goodman, D. Auret, K. Iakoubovskii, G.J. Adriaenssens, K. Jacobs, I. Moerman, Nuclear Instr. Meth. in Physics Research B 175 (2001) 148.

[56] R.G. Wilson, R.N. Schwartz, C.R. Abernathy, S.J. Pearton, N. Newman, M. Rubin, T. Fu, J.M. Zavada, Appl. Phys. Lett. 65 (1994) 992.

[57] J.M. Zavada, R.A. Mair, C.J. Ellis, J.Y. Lin, H.X. Jiang, R.G. Wilson, P.A. Grudowski, R.D. Dupuis, Appl. Phys. Lett. 75 (1999) 790.

[58] J.M. Zavada, C.J. Ellis, J.Y. Lin, H.X. Jiang, J.T. Seo, U. Hömmerich, M. Thaik, R.G. Wilson, P.A. Grudowski, R.D. Dupuis, Mater. Sci. Eng. B 81 (2001) 127.

[59] J.M. Zavada, M. Thaik, U. Hömmerich, J.D. MacKenzie, C.R. Abernathy, S.J. Pearton, R.G. Wilson, J. Alloy Compounds 200 (2000) 207.

[60] J.B. Gruber, B. Zandi, H.J. Lozykowski, W.M. Jadwisienczak, I. Brown, J. Appl. Phys. 89 (2001) 7973.

[61] S. Kim, S.J. Rhee, D.A. Turnbull, X. Li, J.J. Coleman, S.G. Bishop, Appl. Phys. Lett. 71 (1997) 2662.

[62] B. Pipeleers, S. Hogg, A. Vantomme, Nuclear Instr. Meth. in Physics Research B 206 (2003) 95. 


\begin{tabular}{|c|c|c|c|c|c|c|c|c|c|}
\hline Element & Method & $\begin{array}{l}\text { Fluence } \\
{\left[\mathrm{cm}^{-2}\right]}\end{array}$ & Energy [keV] & $\begin{array}{l}T_{\mathrm{A}}\left[{ }^{\circ} \mathrm{C}\right], \\
\mathrm{t}[\mathrm{min}]\end{array}$ & Atmosphere & $\begin{array}{l}T_{\mathrm{A}}\left[{ }^{\circ} \mathrm{C}\right] \\
\mathrm{t}[\mathrm{min}]\end{array}$ & Atmosphere & lattice location or symmetry & \\
\hline $\mathrm{Er}$ & IR PL & $6 \times 10^{14}+6 \times 10^{14} \mathrm{O}$ & 160 & 600,30 & $\mathrm{~N}_{2}$ flow & 900,2 & $\mathrm{~N}_{2}$ flow & $70-100 \% \mathrm{~S}_{\mathrm{Ga}}$ & [12] \\
\hline Er & IR PL & $5 \times 10^{15}$ & 160 & 1000,30 & $\mathrm{~N}_{2}$ flow & 1200,20 & $\mathrm{~N}_{2} 1 \mathrm{GPa}$ & $? \% \mathrm{~S}_{\mathrm{Ga}}$ & {$[14]$} \\
\hline $\mathrm{Er}$ & $\mathrm{IR}+$ vis $\mathrm{PL}$ & $5 \times 10^{15}$ & 150 & 550 hot & vacuum & 1200,20 & $\mathrm{~N}_{2} 1.5 \mathrm{GPa}$ & $>50 \% \mathrm{~S}_{\mathrm{Ga}}$ & {$[18]$} \\
\hline $\operatorname{Pr}$ & $\mathrm{IR}+$ vis PL & $1 \times 10^{15}$ & 300 & 1050,60 & Ar flow & & & & {$[20,21]$} \\
\hline $\mathrm{Er}$ & vis PL upc & $1-2 \times 10^{15}$ & 200 & 1100,60 & $\mathrm{O}_{2}$ or Ar flow & & & & {$[22]$} \\
\hline $\begin{array}{l}\text { Er, } \\
\mathrm{Eu}\end{array}$ & $\begin{array}{l}\text { vis } C L \\
\text { vis } C L \\
\end{array}$ & $\begin{array}{l}1 \times 10^{15} \\
1 \times 10^{15}\end{array}$ & $\begin{array}{l}170 \mathrm{ch} \\
200 \mathrm{ch}\end{array}$ & $\begin{array}{l}950,30 \\
1050,30\end{array}$ & $\begin{array}{l}\mathrm{N}_{2} \\
\mathrm{~N}_{2}+\mathrm{NH}_{3} \\
\end{array}$ & & & & [23] \\
\hline $\mathrm{Er}$ & IR PL & $5 \times 10^{14}$ & 1000 & $1300,0.25-7$ & $\mathrm{~N}_{2}$ flow, RTA & & & & {$[24]$} \\
\hline $\operatorname{Pr}$ & $\mathrm{IR}+$ vis $\mathrm{PL}$ & $5.7 \times 10^{13}$ & 300 & $\begin{array}{l}1050,10 \\
1150,10\end{array}$ & $\begin{array}{l}\mathrm{N}_{2} \\
\mathrm{NH}_{3}\end{array}$ & & & & [25] \\
\hline $\mathrm{Sm}$ & vis $\mathrm{CL}$ & $2 \times 10^{14}$ & $14-180 \mathrm{f}$ & 1100,30 & $\mathrm{NH}_{3}$ & & & $C_{3 v}$ symm & [26] \\
\hline $\mathrm{Tb}$ & vis $\mathrm{CL}$ & $?$ & ?f & 1100,30 & $\mathrm{~N}_{2}$ & & & $D_{2}$ symm & {$[27]$} \\
\hline $\mathrm{Er}$ & IR PL & $2 \times 10^{14}+2 \times 10^{15} \mathrm{O}$ & 300 & 800,30 & $\mathrm{NH}_{3}+\mathrm{H}_{2}$ & & & & {$[28]$} \\
\hline $\mathrm{Er}$ & IR PLE & $2 \times 10^{14}+10^{15} \mathrm{O}$ & 300 & 650,60 & $?$ & & & several centers & {$[29,30]$} \\
\hline $\mathrm{Er}$ & IR PLE & $4 \times 10^{12}$ & 280 & 900,30 & $\mathrm{~N}_{2}$ flow & & & 4 centers & {$[31,32]$} \\
\hline $\mathrm{Nd}$ & IR PLE & $1 \times 10^{14}$ & 320 & 1000,90 & $\mathrm{~N}_{2}$ flow & & & 5 centers & [33] \\
\hline Er & IR PLE & $4 \times 10^{13}$ & 280 & 900,30 & $\mathrm{~N}_{2}$ flow & & & 7 centers & [34] \\
\hline Er & IR PLE & $4 \times 10^{13}+\mathrm{Mg}$ & 280 & 900,90 & $\mathrm{~N}_{2}$ flow & & & 9 centers & [35-37] \\
\hline $\mathrm{Tm}$ & $\mathrm{IR}+$ vis CL & $3.5 \times 10^{15}$ & 150 & 400 hot & vacuum & 1000,2 & $\mathrm{~N}_{2}$ RTA & & {$[17]$} \\
\hline $\begin{array}{ll}\text { Dy, } & \text { Er, } \\
\text { Tm }\end{array}$ & $\mathrm{IR}+$ vis CL & $10^{14}-10^{15}$ & $150,17-150 \mathrm{f}$ & 1100,30 & $\begin{array}{l}\mathrm{N}_{2} \text { or } \mathrm{NH}_{3} \\
\text { flow }\end{array}$ & & & possibly several centers & {$[38]$} \\
\hline Sm, Ho & vis $\mathrm{CL}$ & $1.4 \times 10^{14}$ & $15-150 \mathrm{f}$ & 1100,30 & $\mathrm{~N}_{2}$ flow & & & possibly several sites & [39] \\
\hline $\mathrm{Tb}$ & vis PL+CL & $?$ & $? \mathrm{f}$ & 1100,30 & $\mathrm{~N}_{2}$ flow & & & Assumed $C_{3 v}$ symm & {$[40,41]$} \\
\hline $\operatorname{Pr}$ & vis $\mathrm{PL}+\mathrm{CL}$ & $1.4 \times 10^{14}$ & $15-150 \mathrm{f}$ & 1100,60 & $\mathrm{NH}_{3}$ & & & Assumed $C_{3 v}$ symm & {$[42,43]$} \\
\hline$\overline{\mathrm{Eu}}$ & vis $\mathrm{PL}+\mathrm{CL}$ & $?$ & ?f & 1100,30 & $\begin{array}{l}\mathrm{N}_{2} \text { or } \mathrm{NH}_{3} \\
\text { flow }\end{array}$ & & & Assumed $C_{3 v}$ symm & [44] \\
\hline $\mathrm{Er}$ & IR PLE & $4 \times 10^{15}$ & 280 & 900,90 & $\mathrm{~N}_{2}$ flow & & & Several centers & [45] \\
\hline $\mathrm{Er}$ & IR + vis PLE & $5 \times 10^{15}$ & 160 & $650, ?$ & $\mathrm{~N}_{2}$ flow & 1200,20 & $\mathrm{~N}_{2} 1 \mathrm{GPa}$ & $\begin{array}{l}\begin{array}{l}\text { Several centers, } 32 \% \\
\text { displaced }\end{array} \\
\end{array}$ & [19] \\
\hline $\mathrm{Eu}, \mathrm{Pr}$ & vis PL & $5 \times 10^{14}$ & 160 & 1000,2 & $\mathrm{~N}_{2}$ flow, RTA & & & $\begin{array}{l}\mathrm{Pr}+\mathrm{Eu} \text { on } S_{\mathrm{Ga}} \text { but Eu displaced, } \mathrm{Pr} \\
C_{3 v}, \mathrm{Eu} D_{2}\end{array}$ & {$[15,16]$} \\
\hline $\mathrm{Er}$ & IR PLE & $2 \times 10^{15}$ & 800 & $900-1000,30$ & $\mathrm{~N}_{2}$ flow & & & 3 different classes of centers & {$[46,47]$} \\
\hline $\mathrm{Er}$ & IR CL & $1 \times 10^{15}+10^{16} \mathrm{O}$ & 400 & $900,30-60$ & $\mathrm{NH}_{3}$ flow & & & & [48] \\
\hline $\mathrm{Er}$ & IR PLE & $4 \times 10^{15}$ & 280 & Excimer laser & $\mathrm{N}_{2}$ flow & & & & [49] \\
\hline $\mathrm{Er}$ & $\mathrm{IR} E L+\mathrm{PLE}+\mathrm{CL}$ & $1-2 \times 10^{15}+10^{16} \mathrm{O}$ & 350 & $\begin{array}{l}800, \quad 45 \text { or } \\
900,30\end{array}$ & $\mathrm{NH}_{3}$ flow & & & & [50-53] \\
\hline Er & IR + vis PL & $1.3 \times 10^{15}$ & $400-2000 \mathrm{f}$ & 1100,30 & Ar RTA & & & & {$[54]$} \\
\hline Er & vis PL & $4 \times 10^{14}$ & $80 \mathrm{ch}$ & 950,30 & $\mathrm{~N}_{2}$ flow & & & & [55] \\
\hline Er & IR PL & $2 \times 10^{14}+10^{15} \mathrm{O}$ & 300 & $700, ?$ & $?$ & & & & [56] \\
\hline $\operatorname{Pr}$ & IR PL & $5.7 \times 10^{13}$ & 300 & 1050,10 & $\mathrm{~N}_{2}$ & & & & [57] \\
\hline Er & IR PL & $5.7 \times 10^{13}+10^{15} \mathrm{O}$ & 300 & $900-1050,10$ & $\mathrm{~N}_{2}$ & & & & [58-59] \\
\hline
\end{tabular}




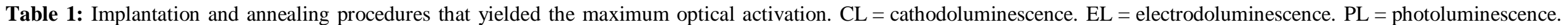

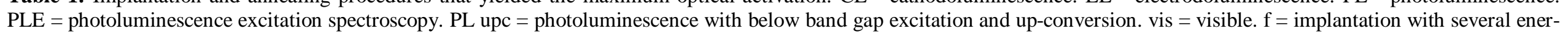

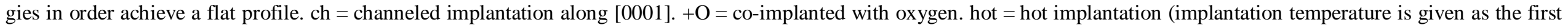
annealing step). RTA = rapid thermal annealing. 